\title{
Redox rich dicobalt macrocycles as templates for multi-electron transformations $\dagger$
}

\author{
Nathaniel K. Szymczak, Louise A. Berben and Jonas C. Peters* \\ Received (in Berkeley, CA, USA) 13th July 2009, Accepted 17th September 2009 \\ First published as an Advance Article on the web 6th October 2009 \\ DOI: $10.1039 /$ b913946j
}

Pyridazine-templated dicobalt macrocycles reversibly support five oxidation states with unusually positive $\mathrm{Co}^{\mathrm{II}} / \mathrm{Co}^{\mathrm{I}}$ redox couples, and are also active proton reduction electrocatalysts.

The reversible transformation of substrates by several electron equivalents is a key goal of chemical energy storage. ${ }^{1}$ Toward this aim, extensive effort has been devoted to study catalysts that mediate the multi-electron reduction of substrates including protons, $\mathrm{CO}_{2}$ and $\mathrm{N}_{2}{ }^{2}$ In order to achieve such transformations with minimal energy input, catalysts that operate at low overpotentials are desired. Toward this end, $\mathrm{we}^{3}$ and others ${ }^{4}$ have been investigating cobalt tetra-imine macrocyclic complexes that are able to mediate the reduction of weak acids to $\mathrm{H}_{2}$ at comparatively low overpotentials. Using a $\mathrm{Co}(\mathrm{dmgBF})_{2}\left(\mathrm{CH}_{3} \mathrm{CN}\right)_{2}\left(\mathrm{dmgBF}_{2}=\right.$ difluoroboryldimethylglyoxime) precatalyst, near-quantitative Faradaic yields can be obtained for the electrocatalytic reduction of $\mathrm{H}^{+}$using $\mathrm{CF}_{3} \mathrm{COOH}$ as the proton source, with promising kinetic efficiency at an overpotential of less than $100 \mathrm{mV}^{3}$ While the interconversion of proton and electron equivalents does not necessarily require more than one metal site (to effect twoelectron reduction), the reduction of more highly-oxidized substrates such as $\mathrm{CO}_{2}$ or $\mathrm{NO}_{3}{ }^{-}$may be facilitated by multimetallic scaffolds. Such molecular constructs featuring more than one metal site can potentially transfer multi-electron equivalents, as well as facilitate the binding of weak donor ligands through cooperative pathways.

Within this context, our group has begun to target bimetallic analogues of various $\mathrm{Co}\left(\mathrm{dmgBF}_{2}\right)_{2} \mathrm{~L}_{2}$ complexes that have the ability to undergo several $(>4)$ reversible redox events with the ultimate goal of transferring the multiple redox equivalents to substrates of interest. Herein, we describe a series of dicobalt macrocycles that support up to five oxidation states and are also active electrocatalysts for proton reduction at comparatively low overpotentials.

A bimetallic macrocycle that incorporates two Co-centers within a planar imine environment can be realized using pyridazine-based building blocks (Fig. 1). ${ }^{5}$ The pyridazine dioxime precursors are accessible from the appropriate pyridazine dicarbonyl following condensation with hydroxylamine. An anionic borate linkage has been included in the design presented here to decrease coulombic repulsions between $\mathrm{H}^{+}$and positively-charged Co-species.

Department of Chemistry, Massachusetts Institute of Technology, Cambridge, Massachusetts 02139,USA.E-mail: jcpeters@mit.edu

$\dagger$ Electronic supplementary information (ESI) available: Complete experimental details and crystal structures. CCDC 740044-740052. For ESI and crystallographic data in CIF or other electronic format see DOI: $10.1039 / \mathrm{b} 913946 \mathrm{j}$

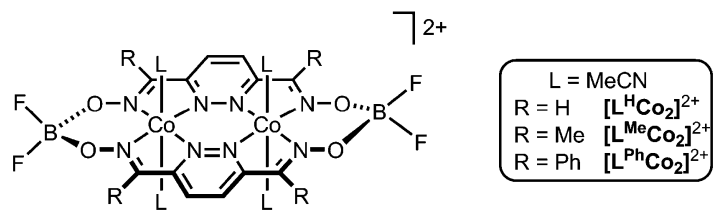

Fig. 1 Cobalt complexes and abbreviations used in this study.

A series $\left(\mathrm{R}=\mathrm{H}, \mathrm{Me}, \mathrm{Ph}\right.$; Fig. 1) of new bimetallic $\mathrm{Co}^{\mathrm{II}} \mathrm{Co}^{\mathrm{II}}$ complexes bearing this ligand architecture was prepared from the respective dioxime precursors by reaction with $\mathrm{Co}(\mathrm{OAc})_{2}$ and $\mathrm{BF}_{3} \cdot \mathrm{Et}_{2} \mathrm{O}$ (see the ESI $\dagger$ ). These complexes were characterized structurally, spectroscopically and electrochemically. The solidstate structures of the set of $\left[\mathbf{L}^{\mathrm{R}} \mathbf{C o}_{2}\right]^{2+}$ complexes reveal tetragonally distorted 6-coordinate geometries around each cobalt center with solvent ligands occupying the axial sites (Fig. 2).

The electrochemistry of the set of $\left[\mathbf{L}^{\mathrm{R}} \mathbf{C o}_{\mathbf{2}}\right]^{2+}$ complexes was examined by cyclic voltammetry (Table 1). For each complex, the cathodic scan revealed at least two electrochemicallyreversible $1 \mathrm{e}^{-}$reduction events (ascribed to $\mathrm{Co}^{\mathrm{II}} \mathrm{Co}^{\mathrm{II}} / \mathrm{Co}^{\mathrm{II}} \mathrm{Co}^{\mathrm{I}}$ and $\mathrm{Co}^{\mathrm{II}} \mathrm{Co}^{\mathrm{I}} / \mathrm{Co}^{\mathrm{I}} \mathrm{Co}^{\mathrm{I}}$ couples; Table 1$) .{ }^{6}$ The Co-based reduction events are sufficiently well separated $\left(K_{\mathrm{c}}=2.6 \times 10^{4}-9.5 \times\right.$ $10^{4}$ for $\left.\left[\mathbf{L}^{\mathrm{R}} \mathrm{Co}_{2}\right]^{2+} ; \mathrm{L}=\mathrm{L}^{\mathrm{H}}, \mathrm{L}^{\mathrm{Me}}, \mathrm{L}^{\mathrm{Ph}}\right)$ to suggest that the mixed-valence species should be reasonably stable. Following the metal-based reduction events, other presumed ligandcentered reduction events are noted at more negative potentials based on comparison with a $\mathrm{Zn}_{2}$-analogue that has been independently prepared and characterized, (see the $\mathrm{ESI} \dagger$ ) $\left[\mathbf{L}^{\mathbf{M e}} \mathbf{Z} \mathbf{n}_{2}\right]^{2+}$. Scanning in the anodic direction for $\left[\mathbf{L}^{\mathbf{R}} \mathbf{C o}_{2}\right]^{2+}$ revealed the presence of two $1 \mathrm{e}^{-}$reversible or quasi-reversible oxidation events. $^{7}$

Because well-defined bimetallic $\mathrm{Co}^{\mathrm{II}} \mathrm{Co}^{\mathrm{I}}$ complexes are still unknown, the isolation of mixed-valence $\mathrm{Co}^{\mathrm{II}} \mathrm{Co}^{\mathrm{I}}$ complexes was pursued. The $\mathrm{Co}^{\mathrm{II}} \mathrm{Co}^{\mathrm{I}}$ complexes were generated via controlled potential electrolyses and were isolated following the removal of the $\left[{ }^{n} \mathrm{Bu}_{4} \mathrm{~N}\right]\left[\mathrm{ClO}_{4}\right]$ electrolyte by washing with DME several times. The UV-visible spectrum of each complex exhibits broad low-energy IVCT bands at 874, 947 and $875 \mathrm{~nm}$ for $\left[\mathbf{L}^{\mathrm{H}} \mathbf{C o}^{\mathrm{II}} \mathbf{C o}^{\mathbf{I}}\right]^{+}, \quad\left[\mathbf{L}^{\mathrm{Me}} \mathbf{C o}^{\mathrm{II}} \mathbf{C o}^{\mathbf{I}}\right]^{+}$, and $\left[\mathbf{L}^{\mathrm{Ph}} \mathbf{C o}^{\mathrm{II}} \mathbf{C o}^{\mathbf{I}}\right]^{+}$, respectively. The X-Band EPR spectrum in DMF glass for $\left[\mathbf{L}^{\mathbf{M e}} \mathbf{C o}^{\mathbf{I I}} \mathbf{C o} \mathbf{I}\right]$ at $77 \mathrm{~K}$ (Fig. 3) reveals an axial pattern with $g$ tensors of $g_{\perp}=2.26\left(A_{\perp}=22 \mathrm{G}\right)$ and $g_{\|}=2.02\left(A_{\|}=76 \mathrm{G}\right)$, consistent with low-spin $\mathrm{Co}$ (II) in a tetragonally-distorted coordination environment. ${ }^{9}$ Similar EPR spectra have been reported for mononuclear $\mathrm{CoL}_{2}\left(\mathrm{dmgBF}_{2}\right)_{2}$ systems $(\mathrm{L}=\mathrm{MeCN}, \mathrm{MeOH}) .^{10}$

The solid-state structure of $\left[\mathbf{L}^{\mathbf{M e}} \mathbf{C o}^{\text {II }} \mathbf{C o}^{\mathbf{I}}\right]^{+}$, obtained by diffusion of diethyl ether into an acetonitrile solution (Fig. 2d), shows that the coordination environments of the 
Table 1 Electrochemical data for $\left[\mathbf{L}^{\mathbf{R}} \mathbf{C o}_{2}\right]$-type complexes ${ }^{a}$

\begin{tabular}{|c|c|c|c|c|c|c|}
\hline Complex & $\mathrm{Co}^{\mathrm{II}} \mathrm{Co}^{\mathrm{II}} / \mathrm{Co}^{\mathrm{II}} \mathrm{Co}^{\mathrm{I}}$ & $\mathrm{Co}^{\mathrm{II}} \mathrm{Co}^{\mathrm{I}} / \mathrm{Co}^{\mathrm{I}} \mathrm{Co}^{\mathrm{I}}$ & $K_{\mathrm{c}}^{b}$ & $\mathrm{Co}^{\mathrm{II}} \mathrm{Co}^{\mathrm{II}} / \mathrm{Co}^{\mathrm{II}} \mathrm{Co}^{\mathrm{III}}$ & $\mathrm{Co}^{\mathrm{II}} \mathrm{Co}^{\mathrm{III}} / \mathrm{Co}^{\mathrm{III}} \mathrm{Co}^{\mathrm{III}}$ & $K_{\mathrm{c}}^{b}$ \\
\hline$\left[\mathbf{L}^{\mathrm{H}} \mathrm{Co}_{2}\right]^{2+}$ & 0.12 & -0.14 & $2.6 \times 10^{4}$ & 1.13 & 1.32 & $1.4 \times 10^{3}$ \\
\hline$\left[\mathbf{L}^{\mathrm{Me}} \mathrm{Co}_{2}\right]^{2+}$ & -0.01 & -0.30 & $9.5 \times 10^{4}$ & 1.10 & 1.21 & $1.6 \times 10^{3}$ \\
\hline$\left[\mathbf{L}^{\mathrm{Ph}} \mathrm{Co}_{2}\right]^{2+}$ & 0.09 & -0.17 & $2.8 \times 10^{4}$ & 1.07 & 1.28 & $3.9 \times 10^{3}$ \\
\hline$\left[\mathbf{L}^{\left.\mathbf{H}_{*} \mathbf{C o}_{2}\right]^{4+}}\right.$ & 0.18 & -0.04 & $5.3 \times 10^{3}$ & 1.16 & 1.35 & $1.6 \times 10^{3}$ \\
\hline
\end{tabular}

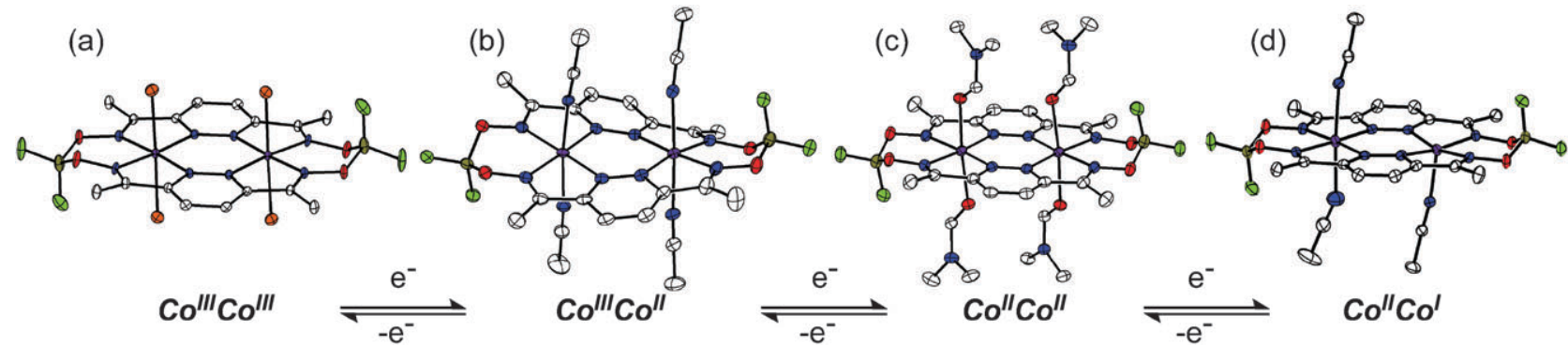

Fig. 2 Solid state structures of $\left[\mathbf{L}^{\mathrm{Me}} \mathbf{C o}^{\mathrm{III}} \mathbf{C o}^{\mathrm{III}} \mathbf{B r}_{4}\right],\left[\mathbf{L}^{\mathbf{M e}} \mathbf{C o}{ }^{\mathrm{III}} \mathbf{C o}{ }^{\mathrm{II}}\right]^{3+},\left[\mathbf{L}^{\mathbf{M e}} \mathbf{C o}^{\mathrm{II}} \mathbf{C o} \mathbf{o}^{\mathrm{II}}\right]^{2+}$ and $\left[\mathbf{L}^{\mathrm{Me}} \mathbf{C o}^{\mathrm{II}} \mathbf{C o}^{\mathrm{I}}\right]^{+}$with axial solvent ligands $(\mathrm{DMF}$ and $\mathrm{MeCN})$.

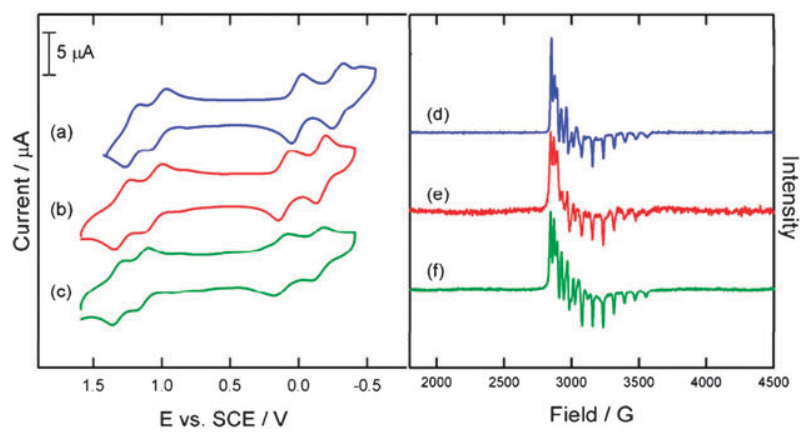

Fig. 3 Cyclic voltammetry (left) of $\left[\mathbf{L}^{\mathbf{M e}} \mathbf{C o}_{2}\right]^{2+}(\mathrm{a}),\left[\mathbf{L}^{\mathrm{Ph}} \mathbf{C o}_{2}\right]^{2+}$ (b) and $\left[\mathbf{L}^{\mathrm{H}} \mathbf{C o}_{2}\right]^{2+}$ (c) $(0.2 \mathrm{mM})$ in $0.1 \mathrm{M}\left[{ }^{n} \mathrm{BuN}_{4}\right]\left[\mathrm{ClO}_{4}\right] \mathrm{MeCN}$, scan rate $=$ $100 \mathrm{mV} \mathrm{s}^{-1}$. EPR spectra (right) of $\left[\mathbf{L}^{\mathbf{M e}} \mathbf{C o}^{\mathbf{I I}} \mathbf{C o}^{\mathbf{I}}\right]^{+}$(d), $\left[\mathbf{L}^{\mathbf{P h}} \mathbf{C o}^{\mathbf{I I}} \mathbf{C o}^{\mathbf{I}}\right]^{+}$ (e), and $\left[\mathbf{L}^{\mathbf{H}} \mathbf{C o} \mathbf{o}^{\mathrm{II}} \mathbf{C o}^{\mathbf{I}}\right]^{+}$(f) (in DMF glass at $77 \mathrm{~K}, 9.377 \mathrm{GHz}$ ).

two Co centers are different, with one 5-coordinate square pyramid and one 6-coordinate octahedron. However, the structure was disordered over two crystallographically identical sites, so a meaningful discussion of the variances in the bond lengths and angles cannot be presented. The structural characterization of a related $\mathrm{Co}^{\mathrm{II}} \mathrm{Co}^{\mathrm{I}}$ complex is presented in the ESI (Fig. S9 $\dagger$ ). To our knowledge, these derivatives represent the only well characterized $\mathrm{Co}^{\mathrm{II}} \mathrm{Co}^{\mathrm{I}}$ bimetallics. There are two reported examples of related mixed valency in cobalt complexes of higher nuclearity. ${ }^{11}$

Based on the EPR spectra of $\left[\mathbf{L}^{\mathbf{R}} \mathbf{C o}^{\mathbf{I I}} \mathbf{C o}^{\mathbf{I}}\right]^{+}$and analysis of the solid-state structure of $\left[\mathbf{L}^{\mathbf{M e}} \mathbf{C o}^{\mathbf{I I}} \mathbf{C o}^{\mathbf{I}}\right]^{+}$, two electronically isolated cobalt centers are plausible. However, the electronic absorption spectrum of $\left[\mathbf{L}^{\mathbf{M e}} \mathbf{C o}^{\mathbf{I I}} \mathbf{C o} \mathbf{0}^{\mathbf{I}}\right.$ exhibits a low-energy band at $\nu_{\max }=10560 \mathrm{~cm}^{-1}\left(\varepsilon=4723 \mathrm{~L} \mathrm{~mol}^{-1} \mathrm{~cm}^{-1}\right)$ with a bandwidth at half-height, $\Delta \nu_{\frac{1}{2}}=2315 \mathrm{~cm}^{-1}$. Based on these features, a Hush-type analysis can be used to estimate the extent of delocalization in solution for this system. ${ }^{12}$ Accordingly, $\left[\mathbf{L}^{\mathbf{M e}} \mathbf{C o}^{\mathbf{I I}} \mathbf{C o}^{\mathbf{I}^{+}}\right]^{+}$is consistent with a Class II-III mixed valence species by the Robin-Day classification system, ${ }^{13}$ or a species on the borderline between a moderately and strongly coupled system.
In order to explore the range of oxidation states synthetically accessible in these bimetallic systems, $\left[\mathbf{L}^{\mathbf{M e}} \mathbf{C o}^{\mathbf{I I}} \mathbf{C o}^{\mathbf{I}^{+}}\right]^{+}$was treated with 1 equiv. of $\mathrm{PhIO}$ at $-40{ }^{\circ} \mathrm{C}$ to provide the mixed-valence complex $\left[\mathbf{L}^{\mathbf{M e}} \mathbf{C o}^{\mathbf{I I}} \mathbf{C o}^{\mathbf{I I I}}\right]^{3+}$, with concomitant release of $\mathrm{PhI}$. The mixed-valence $\mathrm{Co}^{\mathrm{II}} \mathrm{Co}^{\mathrm{III}}$ product was isolated and characterized by X-ray diffraction (Fig. 2b), EPR spectroscopy, and electronic absorption spectrophotometry. A broad low-energy IVCT band is present at $10930 \mathrm{~cm}^{-1}\left(\varepsilon=880 \mathrm{~L} \mathrm{~mol}^{-1} \mathrm{~cm}^{-1}\right)$, although the band shape is not sufficiently resolved to allow a Hush-type analysis. The band's insensitivity to changes in solvent polarity is consistent with a strongly coupled system.

To try to generate the fully oxidized $\mathrm{Co}^{\mathrm{III}} \mathrm{Co}^{\mathrm{III}}$ complex, $\left[\mathbf{L}^{\mathrm{Me}} \mathbf{C o}^{\mathrm{III}} \mathbf{C o}^{\mathrm{III}}\right]^{4+}$, a series of oxidants and conditions were assayed. In all cases, intractable decomposition occurred in the absence of halide co-additives. Replacement of the $\mathrm{MeCN}$ axial ligands with $\mathrm{Br}^{-}$ligands enabled isolation of the well defined oxidation product $\left[\mathbf{L}^{\mathbf{M e}} \mathbf{C o}^{\mathbf{I I I}} \mathbf{C o}^{\mathbf{I I I}} \mathbf{B r}_{\mathbf{4}}\right]$. Replacement of the $\mathrm{O}-\mathrm{H}-\mathrm{O}$ bridge with an $\mathrm{O}-\mathrm{BF}_{2}-\mathrm{O}$ linkage from the analogous $\left[\mathbf{C o}^{\mathbf{I I I}} \mathbf{C o}^{\mathbf{I I I}} \mathbf{B r}_{\mathbf{4}}\right]$ species generated structurally characterized $\left[\mathbf{L}^{\mathbf{M e}} \mathbf{C o}^{\text {III }} \mathbf{C o}^{\text {III }} \mathbf{B r}_{4}\right]$ (Fig. 2a). The crystallographic determination of $\left[\mathbf{L}^{\mathbf{M e}} \mathbf{C o}_{2}\right]^{n+}$ complexes in four distinct states of oxidation has thus been achieved.

For comparison, we investigated the behavior of a previously known dinuclear Co-pyridazine complex that contains propyl instead of difluoroborylate linkages $([\mathrm{R}=\mathrm{H}$, abbreviated as $\left.\left[\mathbf{L}^{\mathbf{H}_{*}} \mathbf{C o}_{2}\right]^{4+}\right)$. Initially reported by Brooker and co-workers, ${ }^{5}$ the reduction events of $\left[\mathbf{L}^{\mathbf{H}_{*}^{*}} \mathbf{C o}_{2}\right]^{4+}$ occur at slightly more positive potentials than those for other $\left[\mathbf{L}^{\mathbf{R}} \mathbf{C o}_{2}\right]^{2+}$ complexes $\left(+0.18\right.$ and $-0.04 \mathrm{~V}$ vs. SCE for $\mathrm{Co}^{\mathrm{II}} \mathrm{Co}^{\mathrm{II}} / \mathrm{Co}^{\mathrm{II}} \mathrm{Co}^{\mathrm{I}}$ and $\mathrm{Co}^{\mathrm{II}} \mathrm{Co}^{\mathrm{I}} / \mathrm{Co}^{\mathrm{I}} \mathrm{Co}^{\mathrm{I}}$, respectively). The reduction events are sufficiently well-separated $\left(K_{\mathrm{c}}=5.3 \times 10^{3}\right)$ that a mixedvalence $\mathrm{Co}^{\mathrm{I}} \mathrm{Co}^{\mathrm{II}}$ species should also be stable, as previously proposed from spectroelectrochemical data. ${ }^{5}$ We therefore targeted its isolation and structural characterization for comparison with disordered $\left[\mathbf{L}^{\mathbf{M e}} \mathbf{C o}^{\mathbf{I I}} \mathbf{C o}^{\mathbf{I}}\right]^{+}$.

Using a modified synthesis ${ }^{14}$ from that originally reported by Brooker, ${ }^{5}\left[\mathbf{L}^{\mathbf{H} *} \mathbf{C o}_{2}\right]^{4+}$ was prepared by transmetalation 
from the corresponding $\mathrm{Pb}_{2}$-macrocycle. After controlled potential electrolysis, both the one-electron and two-electron reduced complexes were isolated, and structurally (ESI, Fig. S8 and S9†) and spectroscopically characterized. The electronic absorption spectrum of $\left[\mathbf{L}^{\mathbf{H} *} \mathbf{C o}^{\mathbf{I}} \mathbf{C o}^{\mathbf{I}}\right]^{3+}$ exhibits a broad, low-energy band at $975 \mathrm{~nm}\left(\varepsilon_{970}=2704 \mathrm{~L} \mathrm{~mol}^{-1} \mathrm{~cm}^{-1}\right.$; FWHM $=2196 \mathrm{~cm}^{-1}$ ), which is consistent with a Class II-III system as for $\left[\mathbf{L}^{\mathbf{M e}} \mathbf{C o}^{\mathbf{I I}} \mathbf{C o}^{\mathbf{I}}\right]^{+}$. The EPR spectrum of $\left[\mathbf{L}^{\mathbf{H} * \mathbf{C o}} \mathbf{o}^{\mathbf{I I}} \mathbf{C o}^{\mathbf{I}}\right]^{3+}$ in DMF glass at $77 \mathrm{~K}$ affords a similar axial pattern.

Chemical reactivity studies showed that in the presence of a proton source such as $\mathrm{HBF}_{4}$, the fully reduced complex $\left[\mathbf{L}^{\mathbf{H} *} \mathbf{C o}^{\mathbf{I}} \mathbf{C o}^{\mathbf{I}}\right]^{2+}$ first reacts to form the mixed-valence species, $\left[\mathbf{L}^{\mathbf{H} *} \mathbf{C o}{ }^{I \mathbf{I}} \mathbf{C o}^{\mathbf{I}}\right]^{3+}$, which is further oxidized to form the parent

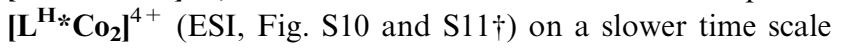
than the first oxidation, with $\sim 95 \%$ conversion and without the appearance of any additional intermediates, even at $-40{ }^{\circ} \mathrm{C}$. The step-wise oxidation would appear to disfavor an $\mathrm{H}_{2}$ forming mechanism, where two $\mathrm{Co}-\mathrm{H}$ centers react intramolecularly to release $\mathrm{H}_{2}$ and the corresponding $\left[\mathbf{L}^{\mathbf{H}} * \mathbf{C o}_{2}\right]^{4+}$ product. Intrigued by this result, we sought to probe the reactivity of $\left[\mathbf{L}^{\mathbf{R}} \mathbf{C o}_{2}\right]^{n+}$ with protons by electrochemical methods.

Upon titration with a strong acid such as 2,6-dichloroanilinium tetrafluoroborate, ${ }^{15}$ a cathodic shift in the $\mathrm{Co}^{\mathrm{II}} \mathrm{Co}^{\mathrm{I}} / \mathrm{Co}^{\mathrm{I}} \mathrm{Co}^{\mathrm{I}}$ redox couple was observed along with an increase in the peak current (Fig. 4; ESI Fig. S22 and S23†). This behavior is consistent with a catalytic process in which an electroactive species reacts at the electrode at a faster rate than the scan rate of the electrochemical experiment. The intensity of the catalytic wave for $\left[\mathbf{L}^{\mathbf{M e}} \mathbf{C o}_{2}\right]^{2+}$ increases dramatically upon the addition of acid equivalents, and the current response maintains a peak shape throughout the additions, which suggests that the electrocatalytic reduction of protons is limited by diffusion to the electrode surface. ${ }^{16}$ More detailed studies are in progress.

In summary, a new series of bimetallic macrocycles has been prepared that incorporate zwitterionic difluoroboryl linkages into a pyridazine-templated construct. These were initially targeted within the context of electrocatalytic proton reduction
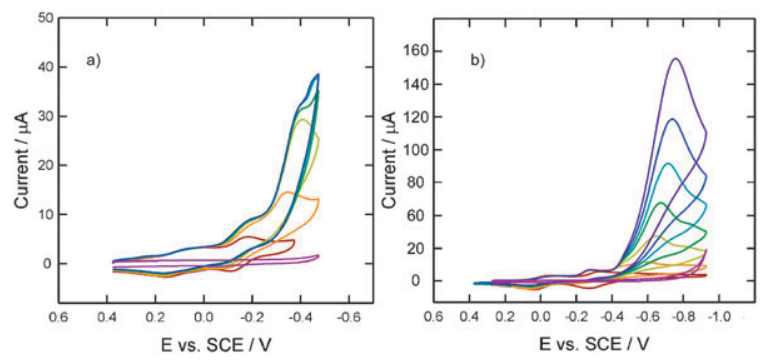

Fig. 4 (a) Cyclic voltammograms of $\left[\mathbf{L}^{\mathbf{H}} \mathbf{C o}_{2}\right]^{2+}(0.2 \mathrm{mM})$ in the presence of increasing amounts of 2,6-dichloroanilinium tetrafluoroborate (bottom to top; the lowest fuchsia trace is the control with acid only) in $0.1 \mathrm{M}\left[{ }^{n} \mathrm{Bu}_{4} \mathrm{~N}\right]\left[\mathrm{ClO}_{4}\right] \mathrm{MeCN}(0.2 \mathrm{mM}): 0,1.0,2.5,4.5,7.0$ and $9.9 \mathrm{mM}$, and (b) the same experiment with $\left[\mathbf{L}^{\mathbf{M e}} \mathbf{C o}_{2}\right]^{2+}(0.2 \mathrm{mM})$ (bottom to top; the lowest fuchsia trace is the control with acid only): $0,1.0,2.5,4.5,7.0,9.9$ and $13.7 \mathrm{mM}$ 2,6-dichloroanilinium tetrafluoroborate. Scan rate $=100 \mathrm{mV} \mathrm{s}^{-1}$. at low reduction potentials because the management of protons and electrons is a critical step that needs to be addressed if one wants to later redirect such reactants toward other substrates. The macrocycle complexes were also found to accommodate five redox states, including unusual mixedvalence complexes of $\mathrm{Co}^{\mathrm{II}} \mathrm{Co}^{\mathrm{I}}$ and $\mathrm{Co}^{\mathrm{II}} \mathrm{Co}^{\mathrm{III}}$. Multi-metallic scaffolds such as these are attractive complexes to explore within the context of directing cooperative substrate binding and subsequent multi-electron transfer reactions. Their ability to support four reversible one-electron redox events across two nearby metal centers underscores this latter point.

This work was generously supported by BP and an NSF Center for Chemical Innovation grant (Grant CHE-0802907). We thank Dr Yunho Lee and Dr Sebastian Stoian for EPR assistance, and Dr Bruce Brunschwig for helpful discussions.

\section{Notes and references}

1 N. S. Lewis and D. G. Nocera, Proc. Natl. Acad. Sci. U. S. A., 2006, 103, 15729.

2 For lead reviews see: D. L. DuBois and M. Rakowski DuBois, Acc. Chem. Res., 2009, DOI: 10.1021/ar900110c; E. E. Benson, C. P. Kubiak, A. J. Sathrum and J. M. Smieja, Chem. Soc. Rev., 2009, 38, 89; V. Artero and M. Fontecave, Coord. Chem. Rev., 2005, 249, 1518; J. C. Peters and M. P. Mehn, in Activation of Small Molecules, Wiley-VCH, Weinheim, 2006, ch. 3.

$3 \mathrm{X} . \mathrm{Hu}$, B. M. Cossairt, B. S. Brunschwig, N. S. Lewis and J. C. Peters, Chem. Commun., 2005, 4723; X. L. Hu, B. S. Brunschwig and J. C. Peters, J. Am. Chem. Soc., 2007, 129, 8988.

4 M. Razavet, V. Artero and M. Fontecave, Inorg. Chem., 2005, 44, 4786; C. Baffert, V. Artero and M. Fontecave, Inorg. Chem., 2007, 46, 1817.

5 S. Brooker, R. J. Kelly and P. G. Plieger, Chem. Commun., 1998, 1079.

6 These processes were assigned as electrochemically reversible based on the invariance of the peak position with scan rate, as well as the linear relationship between the peak current and the square root of the scan rate over three orders of magnitude.

7 These processes were assigned as quasi-reversible based on the variance of the peak position with scan rate.

8 C. Creutz, Prog. Inorg. Chem., 1983, 30, 1.

9 Spectra acquired at $4 \mathrm{~K}$ were similar in appearance, and feature a small shift for the $g$ tensors (2.29 and 2.04).

10 A. Bakac, M. E. Brynildson and J. H. Espenson, Inorg. Chem., 1986, 25, 4108.

11 F. Arena, C. Floriani and P. F. Zanazzi, J. Chem. Soc., Chem. Commun., 1987, 183; T. L. Schull, L. Henley, J. R. Deschamps, R. J. Butcher, D. P. Maher, C. A. Klug, K. Swider-Lyons, W. J. Dressick, B. Bujoli, A. E. Greenwood, L. K. B. Congiardo and D. A. Knight, Organometallics, 2007, 26, 2272.

12 N. S. Hush, Prog. Inorg. Chem., 1967, 8, 391; B. S. Brunschwig, C. Creutz and N. Sutin, Chem. Soc. Rev., 2002, 31, 168.

13 M. B. Robin and P. Day, Adv. Inorg. Chem. Radiochem., 1968, 10, 247.

14 An alternative two-step protocol to generate diformyl pyridazine in moderate yields was developed in which diformyl pyridazine is an intermediate en route to the dioxime (see the ESI $\dagger$ ).

$15 \mathrm{p} K_{\mathrm{a}}=5.06$ in $\mathrm{MeCN}$, corresponding to a thermodynamic potential for the $\mathrm{H}^{+} / \mathrm{H}_{2}$ couple at $-0.06 \mathrm{~V}$. For $\mathrm{p} K_{\mathrm{a}}$ values, see: I. Kosuke, in Acid-Base Dissociation Constants in Dipolar Aprotic Solvents, Blackwell Scientific Publications, Oxford, 1990; L. Sooväli, I. Kaljurand, A. Kütt and I. Leito, Anal. Chim. Acta, 2006, 566, 290; for a discussion of thermodynamic potentials of $\mathrm{H}^{+} / \mathrm{H}_{2}$ redox couples, see: G. A. N. Felton, R. S. Glass, D. L. Lichtenberger and D. H. Evans, Inorg. Chem., 2006, 45, 9181.

16 J. M. Savéant and K. B. Su, J. Electroanal. Chem., 1984, 171, 341; C. P. Andrieux, C. Blocman, J. M. Dumas-Bouchiat, F. M'Halla and J. M. Savéant, J. Electroanal. Chem., 1980, 113, 19. 